\title{
CONVERGENCIAS ENTRE LA SOBRENATURALEZA DE ORTEGA, LA EXTERIORIZACIÓN DE STIEGLER Y LA INMUNOLOGÍA DE SLOTERDIJK
}

\author{
CONVERGENCES BETWEEN ORTEGA'S OVER-NATURE, STIEGLER'S \\ EXTERIORIZATION AND SLOTERDIJK'S IMMUNOLOGY
}

\author{
MARCOS ALONSO FERNÁNDEZ \\ marcs.alonso@gmail.com \\ Universidad Autónoma de Madrid
}

RECIBIDO: $02 / 04 / 2018$
ACEPTADO: $17 / 07 / 2018$

Resumen: En este artículo trataremos de exponer el fecundo concepto orteguiano de sobrenaturaleza, un concepto poco utilizado, pero de gran potencia filosófica, especialmente en el ámbito de la filosofía de la técnica. A su vez, trataremos de poner en relación esta idea orteguiana de sobrenaturaleza con algunos desarrollos similares de autores más recientes como Stiegler, con su tesis sobre la exteriorización; y especialmente con Sloterdijk y sus conceptos de parque, esfera e inmunología. Mostraremos cómo estas ideas nos pueden proporcionar muchas claves importantes para entender el tecnificado mundo de hoy

Palabras clave: Sobrenaturaleza, técnica, antropología, Ortega, Stiegler, Sloterdijk.

\begin{abstract}
In this paper we will try to expose Ortega's fertile concept of over-nature, an underutilised concept, but one of great philosophical power, especially within philosophy of technology. While doing so, we will try to conect Ortega's idea of over-nature with some later and comparable developments from authors like Stiegler and his thesis on exteriorization; and especially with Sloterdijk and his concepts of park, sphere and immunology. We will show how these ideas can provide us of many interpretative keys to understand the technological world of today.
\end{abstract}

Keywords: Over-nature, technology, anthropology, Ortega, Stiegler, Sloterdijk.

\section{El concepto de sobrenaturaleza en el pensamiento orteguiano}

Si bien el concepto de sobrenaturaleza no aparece muy desarrollado en la obra de Ortega, y su mención explícita se limita a unos pocos trabajos principalmente Meditación de la técnica-, esto no significa que sea un concepto irrelevante dentro de su producción. Como veremos a continuación, la noción de sobrenaturaleza y otras estrechamente relacionadas adquieren un notable peso específico al llegar Ortega a su madurez filosófica de los años 30. Esto es especialmente claro en el tema de la técnica, un tema presente en las reflexiones de Ortega desde los años 20 pero que a partir de 1930 cobra todavía más 
importancia en sus escritos. El propio Ortega así lo afirma claramente en la introducción al curso ¿Qué es la técnica? donde afirma que "Sin la técnica el hombre no existiría ni habría existido nunca. Así, ni más ni menos” (IX 27) ${ }^{1}$, y que "Hoy el hombre no vive ya en la naturaleza sino que está alojado en la sobrenaturaleza que ha creado, en un nuevo día del génesis, la técnica" (IX 28). Esta importancia que Ortega otorga a la técnica, y que correlativamente hay que conceder también a la sobrenaturaleza por ésta creada, se debe a las bases antropológicas desde las que el filósofo español piensa la técnica. Así pues, la clave que desencadena la acción técnica es precisamente "la constitución extrañísima del hombre; mientras todos los demás seres coinciden con sus condiciones objetivas -con la naturaleza o circunstancia-, el hombre no coincide con ésta sino que es algo ajeno y distinto de su circunstancia" (V 557).

Mas la técnica, y esta es una de las grandes aportaciones de Ortega a la reflexión sobre este tema, "no es lo que el hombre hace para satisfacer sus necesidades" (V 558). Esta idea comúnmente aceptada será contradicha por Ortega. La misión de la técnica va mucho más allá de la mera satisfacción de necesidades, pues "La técnica es la reforma de la naturaleza, de esa naturaleza que nos hace necesitados y menesterosos, reforma en sentido tal que las necesidades quedan a ser posible anuladas por dejar de ser problema su satisfacción" (V 558). La técnica, desde la interpretación orteguiana, no es simplemente una vía alternativa para satisfacer nuestras necesidades, sino una rebelión en toda regla contra la circunstancia: "Es, pues, la técnica, la reacción enérgica contra la naturaleza o circunstancia que lleva a crear entre ésta y el hombre una nueva naturaleza puesta sobre aquélla, una sobrenaturaleza" (V $558)^{2}$.

La sobrenaturaleza será, por tanto, una capa artificial con la que el hombre cubre la naturaleza originaria para domeñarla y hacer más factibles sus deseos. De este modo, esta sobrenaturaleza técnica pasará a suplir a aquella naturaleza originaria y se convertirá desde entonces en su auténtico "hábitat". No hay duda de que esta idea es, como ha afirmado Diéguez, una de las innovaciones conceptuales más importantes de la argumentación orteguiana (Cf. Diéguez, 2013, p. 75), y por ello conviene analizarla en cierto detalle.

\footnotetext{
${ }^{1}$ Para las obras de Ortega citaremos haciendo referencia al tomo de las Obras completas (Ortega y Gasset, José. Obras completas. Tomos I-X. Madrid: Taurus, 2004-2010) en numeración latina seguido del número de página correspondiente.

${ }^{2}$ En Prólogo a Veinte años de caza mayor, del Conde de Yebes (1943), Ortega incluso dirá que este es el destino del hombre: "el hombre está condenado a progresar y esto significa que está condenado a irse cada vez más lejos de la Naturaleza, a construir en su hueco una sobrenaturaleza" (VI 298).
} 
Sólo mediante la creación de una sobrenaturaleza el hombre salva su distanciamiento respecto de la circunstancia y elimina (por asegurarse su satisfacción) las necesidades naturales. Este distanciamiento humano consiste en la forma humana de vivir, en la cual el ser humano siempre está interponiendo mediaciones y difiriendo su acción, al contrario del resto de animales, que se caracterizarían por reaccionar de manera mucho más directa a los estímulos de su entorno $^{3}$. La clave está en que esta sobrenaturaleza se impone a la naturaleza transformándola según la conveniencia humana, adaptándola así al ser humano, en lugar de adaptarse éste a ella ${ }^{4}$. Como explicará Ortega en Meditación de la técnica,

... la técnica, que podemos, desde luego, definir, como la reforma que el hombre impone a la naturaleza en vista de la satisfacción de sus necesidades. Éstas, hemos visto, eran imposiciones de la naturaleza al hombre. El hombre responde imponiendo a su vez un cambio a la naturaleza. Es, pues, la técnica, la reacción enérgica contra la naturaleza o circunstancia que lleva a crear entre ésta y el hombre una nueva naturaleza puesta sobre aquélla, una sobrenaturaleza. (V 558)

La sobrenaturaleza se compone de todas las creaciones humanas, de todo lo artificial que el hombre crea: desde los edificios e infraestructuras hasta los más pequeños artilugios, sin olvidarnos de las creaciones intelectuales ${ }^{6}$. Aunque nos parezca extraño entender esta última vertiente como una sobrenaturaleza, el

\footnotetext{
${ }^{3}$ Esta descripción de la conducta humana frente a la conducta animal, que Ortega lleva a cabo por ejemplo en Ensimismamiento y alteración, resulta demasiado simplista, como los estudios biológicos de las últimas décadas vienen demostrando. El fondo último de la distinción orteguiana entre el hombre ensimismado y el animal alterado, en cambio, sí me parece rescatable, aunque para justificar esto suficientemente habría que llevar a cabo toda una filosofía de la biología, algo que no podemos hacer aquí.

${ }^{4}$ Blumenberg también apunta claramente a esta problemática cuando dice que "la cultura humana es un programa de emergencia para compensar déficit en la dotación biológica" (2011, p. 412), y que "Si afirmamos el fin de la evolución biológica en y por el ser humano, tenemos que aceptar que no hay detención para la evolución instrumental. La evolución instrumental es la compensación necesaria no sólo de la debilidad biológica inicial, sino especialmente de la debilidad biológica definitiva del ser humano. Es posible que el humano termine sucumbiendo por su evolución instrumental. Sólo podría evitarlo si pudiera volver a poner en marcha la selección biológica" (Blumenberg, 2011, p. 412).

${ }^{5}$ Un planteamiento muy similar puede encontrarse también en Gehlen cuando dice, algunos años después que Ortega, que "No hay una «humanidad natural» en sentido estricto: es decir, no hay una sociedad humana sin armas, sin fuego, sin alimentos preparados y artificiales, sin techo y sin formas de cooperación elaborada. La cultura es pues la «segunda naturaleza»: esto quiere decir que es la naturaleza humana, elaborada por él mismo y la única en la que puede vivir. La cultura «anti-natural» es el producto o secuela de un ser único también «anti-natural»" (Gehlen, 1980, p. 42).

${ }^{6} \mathrm{Y}$ en un sentido más profundo, también las ideas, creencias e interpretaciones intelectuales son parte de esta sobrenaturaleza técnica.
} 
propio Ortega ya apuntaba a ello en su curso El Hombre y la gente, justo al comienzo, donde defiende que la labor del hombre es humanizar el mundo, que el hombre

... hace que lo otro -el mundo- se vaya convirtiendo poco a poco en él mismo. El hombre humaniza al mundo, le inyecta, lo impregna de su propia sustancia ideal y cabe imaginar que, un día entre los días, allá en los fondos del tiempo [o sea, hoy], llegue a estar ese terrible mundo exterior tan saturado de hombre, que puedan nuestros descendientes caminar por él como mentalmente caminamos hoy por nuestra intimidad -cabe imaginar que el mundo, sin dejar de serlo, llegue a convertirse en algo así como un alma materializada (V $537-538)^{7}$

Más allá de la fuerza de las expresiones orteguianas, y su sorprendente relación con el mundo con que hoy nos encontramos (un mundo cada vez más cubierto de sobrenaturaleza humana, con nuevas tecnologías como internet, una realidad que encaja sorprendentemente bien en la imagen orteguiana de "alma materializada" ${ }^{\prime}$ ), es importante advertir que el texto no distingue, en lo que se refiere a esta humanización del mundo, entre técnica material y técnica intelectual. De hecho, Ortega da a entender con su expresión "alma materializada" que no se puede distinguir entre ambas, y que la humanización del mundo es a un tiempo material e inmaterial

En todo caso, la lógica que lleva al ser humano a desarrollar la sobrenaturaleza es la siguiente: el hombre, ser artificial por antonomasia, va poco a poco expandiendo esta artificialidad más allá de él mismo, creando una sobrenaturaleza artificial que gana más y más terreno a lo natural. Lo más interesante a este respecto es entender el funcionamiento de esta creciente sobrenaturaleza humana. Pues las distintas técnicas humanas, tanto las intelectuales como las materiales, se apoyan y se superponen unas a otras. Muchas veces no vemos más que la técnica superficial que es, por ejemplo, el

\footnotetext{
${ }^{7}$ Esta cita vuelve a ser utilizada por Ortega en el curso de 1949 El hombre y la gente (Cf. X 145).

${ }^{8}$ Esta expresión del "alma materializada" ha hecho pensar a algunos autores que Ortega está aquí haciendo una anticipación de lo que a partir de los años 90 ha sido internet, como J. Bustamante ha señalado en algunos trabajos (Cf. Bustamante, 2011, p. 17). También Echeverría defiende que la filosofía de la técnica orteguiana y en especial su idea de sobrenaturaleza se adapta como un guante a la realidad de las nuevas tecnologías como internet, lo que este autor denomina como el tercer entorno: "La tesis orteguiana de la sobrenaturaleza, por tanto, se adecúa perfectamente a lo que habitualmente se denomina sociedad de la información" (2000, p. 30). El texto de Misión del bibliotecario antes comentado y su reflexión sobre el significado y función del libro creo que nos da muchas claves para entender el fenómeno de internet, pues el increíble progreso de las computadoras en los últimos 50 años y la creación de la Red han supuesto, de manera similar o incluso superior a la creación de la imprenta, una acumulación de información impresionante, cuyas consecuencias todavía no podemos llegar a atisbar.
} 
automóvil que nos lleva de un lado a otro. Pero la técnica que hace posible el automóvil se asienta en muchas otras técnicas: en la técnica de consecución de los adecuados metales y materiales, en la técnica de la efectiva construcción del automóvil, en la técnica de extracción del petróleo, etc. Pero no sólo eso, porque estas técnicas se asientan también otras más profundas y radicales: no podríamos crear el automóvil sin la creación técnico-interpretativa que es la concepción física del mundo. Pero a su vez esta creación que es la interpretación física del mundo se asienta, por lo menos, en la creación técnico-interpretativa que es nuestro lenguaje.

Para entender este punto resulta conveniente atender a un texto aparentemente menor en la producción orteguiana, el texto titulado Misión del bibliotecario, de 1935. Allí dirá Ortega que

Las ideas que sobre las cosas nos forjamos son el mejor ejemplo de ese instrumental que interponemos entre nosotros y las dificultades que nos rodean. Una idea clara sobre un problema es como un aparato maravilloso que convierte su angustiosa dificultad en holgada y ágil facilidad. (V 359)

Esta comprensión de las ideas como artefactos es de suyo muy interesante, pero Ortega va más allá destacando la importancia crucial de poder conservar estas creaciones llamadas ideas:

Pero la idea es fugaz; (...) Es preciso que la memoria se esfuerce en conservarla. Pero la memoria no es capaz de conservar todas nuestras propias ideas e importa mucho que podamos conservar las de otros hombres. Importa tanto, que es ello lo que más caracteriza nuestra humana condición.

El hombre, dirá Ortega, se diferencia del resto de animales en que su ser es acumulativo, es decir, que retiene "las experiencias vitales de sus antecesores" (V 360), y ello le permite no repetirse indefinidamente como el tigre y progresar. Es gracias a su capacidad de recordar, de tener pasado ${ }^{9}$, y ser, por tanto, una tradición (Cf. IX 578), que el hombre es lo que es: un ser histórico. Mas, y esto es lo decisivo, ¿cómo puede el hombre llevar a cabo esta retención y acumulación de las vidas humanas pasadas, si su natural memoria es tan frágil e insuficiente? La respuesta es obvia: gracias a sus creaciones técnicas e interpretativas, que en lugar de consumirse en su uso se conservan, duran y se transmiten de padres a hijos; una transmisión de experiencia, de soluciones

\footnotetext{
${ }^{9}$ Una capacidad la de recordar y tener pasado que, según Ortega, es creada por la estructura futuriza de su vida: al estar lanzados hacia el futuro rebotamos al pasado para saber cómo orientarnos en el presente.
} 
vitales, sin las cuales el ser humano (y en especial sus indefensas e inmaduras crías) nunca habría podido sobrevivir y perdurar.

En Misión del bibliotecario Ortega mostrará la importancia del libro como una técnica decisiva en la mejora y aumento de la acumulación de experiencia humana: "De aquí que fuera tan importante añadir al instrumento que es la idea un instrumento que facilitase la dificultad de conservar todas las ideas. Este instrumento es el libro" (V 360) ${ }^{10}$. Nótese la expresión orteguiana: el libro es una técnica que se añade a la técnica que ya de por sí es la idea. Las ideas son creaciones intelectuales de un orden análogo a las creaciones técnicas. En todo caso, es significativa la monumental importancia que Ortega otorga a la creación del libro, en cuya invención cifra el verdadero origen de todo el progreso inmenso de los últimos pocos siglos:

\begin{abstract}
Inevitablemente, cuanto más se acumule del pasado, mayor es el progreso. Y así ha acaecido que apenas se resuelve con la imprenta el problema técnico de que haya libros, comienza a acelerarse el tempo de la historia, la velocidad del progreso, llegando en nuestros días a un ritmo que nos parece a nosotros mismos vertiginoso, no digamos lo que parecería a hombres de épocas más tardígradas. (...) Y todo ello debido, principalmente, a la facilidad que el libro representa. (V 360)
\end{abstract}

Empezamos a entrever, pues, cómo el hombre no sólo es intrínsecamente técnico, o lo que es lo mismo, artificial; sino que esta artificialidad suya está asentada sobre toda una tectónica de distintos niveles compuestos de innumerables artificios y técnicas; en definitiva, de distintas sobrenaturalezas. Ortega se contenta con desvelar esta profunda y oculta verdad sin entrar en sus detalles, y sólo puntualmente desarrolla algunas ideas referidas a la técnica del saludo (Cf. IX 338), la técnica de la circulación vial (Cf. IX 302) o la técnica del lenguaje (Cf. 310), por poner algunos ejemplos muy significativos expuestos en El hombre y la gente. No obstante, creo que es ya un gran mérito haber puesto de manifiesto, el entramado técnico, esta sobrenaturaleza en que se apoya toda vida humana, aunque el propio Ortega no lo analizara detenidamente.

En este sentido, es también muy significativo y digno de elogio que Ortega fuera siempre consciente del peligro de esta sobrenaturaleza. Describirla como hace y poner de manifiesto su carácter imprescindible y constitutivo del ser humano, no impide, sino que más bien pide, estar alerta respecto de su problematicidad y el riesgo de que dicha sobrenaturaleza se arruine y se invierta su función original de sustento de la vida humana. Este reconocimiento sobre el peligro de la sobrenaturaleza técnica puede constatarse en muchos lugares de la

\footnotetext{
${ }^{10}$ En este sentido, Ortega dirá en Ideas y creencias que: "el hombre es, por encima de todo, heredero" (V 676).
} 
obra de Ortega, como en la parte final de Meditación de la técnica ${ }^{11}$; aunque probablemente el libro que más toca este punto es La rebelión de las masas, donde Ortega advierte de que el hombre masa es precisamente el resultado de la gran sobrenaturaleza técnica levantada por los siglos precedentes.

Diversos autores e intérpretes de Ortega han recalcado este peligro propio de la sobrenaturaleza. Así, P. Cerezo ya advierte de que "La obra de la cultura, aun siendo expresión de un acto creativo del hombre, genera una segunda naturaleza, la natura naturata, que con su inercia, bloquea y compromete el mismo acto libre que la ha originado" (1984, p. 81). Concretando el problema en el ámbito de la técnica, I. Ellacuría comenta que, debido a la sobrenaturaleza que erige el ser humano, éste tiene "cada vez menos contacto con la naturaleza misma, que, si dificulta a veces la vida humana, es también un tesoro de incitaciones para construir una vida auténticamente humana, vigorosa y no artificial" (Ellacuría, 1996, p. 506). Esto supone, como señala J. Echeverría, que "el hombre contemporáneo se siente más dominado por la tecnología que por la naturaleza" (2000, p. 20), y que, si bien "el canciller Bacon enunció el proyecto de dominar la naturaleza por medio de la ciencia y la técnica, el problema actual consiste en dominar, o cuando menos controlar, las sobrenaturalezas generadas por las acciones tecnológicas" (Echeverría, 2000, p. 20). Esto debe pasar, como bien señala F. J. Martín, por recuperar frente a la lógica del heredero pasivo, inercial, la lógica del creador $(1999$, p. 236), reconociendo así que toda creación humana debe estar "re-creándose día tras día, ad infinitum" (1999, p. 348), evitando que se convierta en naturaleza muerta incorporándola como órgano vivo de nuestro organismo.

La clave antropológica de esta idea consiste en la comprensión que Ortega tendrá del ser humano como un ser que se encuentra en una circunstancia, pero se encuentra en ella incómodo, extrañado, extranjero. Sin embargo, hay que recalcar que con estas tesis Ortega en ningún momento recae en el idealismo. El pensador español siempre es consciente de que no tenemos otro remedio que contar con la circunstancia en todo momento. Pero es un "contar con" que difiere bastante de lo que en su juventud entendió como reabsorción; la circunstancia se opone a nosotros y la única solución posible es intervenirla y modificarla en nuestro favor, creando una sobrenaturaleza humana artificial. La única solución, la única manera posible de vivir humanamente es, pues, la técnica. Una técnica que, en esencia, no es otra cosa que transformación de la circunstancia, y que por

\footnotetext{
${ }^{11}$ J. M. Atencia comenta cómo al final de Meditación de la técnica Ortega lanza "una advertencia de la mayor gravedad: parece que hemos cubierto el ciclo y el hombre ya no crea, sino que se adapta a lo técnico. El hombre creador y poeta, el hombre mago, fabricador, creador de belleza y bondad, adopta una actitud reverencial ante aquello que precisamente lo hizo hombre" (Atencia, 2003, p. 93).
} 
ello está constitutivamente arraigada en el hombre: "Un hombre sin técnica, es decir, sin reacción contra el medio, no es un hombre" (V 559). Y esto por una sencilla razón: porque sin la técnica no podríamos sobreponernos a nuestra radical inadaptación al medio y las dificultades que ello conlleva ${ }^{12}$.

\section{La sobrenaturaleza como proceso de exteriorización: Stiegler}

Uno de los autores que mejor ha entendido y tematizado el problema que venimos discutiendo es B. Stiegler. El filósofo francés entenderá que la génesis del ser humano tiene mucho que ver con lo que denomina como proceso de exteriorización: "A partir de la exteriorización el cuerpo del individuo vivo ya no es sólo el cuerpo: sólo funciona con sus herramientas. No será posible comprender el sistema antropológico arcaico si no se procede a un examen simultáneo del esqueleto, del sistema nervioso central y del utillaje" (Stiegler, 2002, p. 222). Con esta idea Stiegler está yendo algunos pasos más allá de Ortega, apuntando claramente a la imposibilidad de distinguir tajantemente entre órganos corporales y órganos externos o artefactos, señalando la necesidad de entender la sobrenaturaleza humana en directa relación con la naturaleza biológicamente humana. Esta idea es remarcada por Stiegler cuando expone que:

Hemos llegado a esta noción de la herramienta como una verdadera secreción del cuerpo y del cerebro de los Antropoides. Este cuerpo y este cerebro son definidos por la existencia de esta herramienta, y se vuelven indisociables de ella. Considerarlos de manera aislada sería un artificio y por lo tanto hará falta poder estudiar la técnica y su evolución exactamente como se estudiaría la evolución de los organismos vivos (2002, p. 225)

Esta propuesta de llevar a cabo "una especie de zoología o filogenética de la técnica" (Stiegler, 2002, p. 225) es un gran acierto de este filósofo de la técnica. Una idea que curiosamente también podemos ver esbozada en Heisenberg, tal y como H. Arendt nos lo refiere: "los aparatos que manejamos libremente en otro tiempo comienzan a parecer caparazones pertenecientes al cuerpo humano como

\footnotetext{
${ }^{12}$ En este sentido, una de las técnicas primigenias y fundamentales es el control del fuego. En Prólogo a Veinte años de caza mayor del Conde de Yebes, Ortega explica que "el hombre es, ante todo, el animal con el fuego en el puño" (VI 303). Esta caracterización sugiere varias cosas. El fuego es precisamente lo que permite al hombre cierta independencia respecto de su contorno, pues, en un sentido muy básico, el fuego sirve como protección frente a las dos grandes amenazas del hombre primitivo: los depredadores y el frío. El fuego es "el primer gran descubrimiento del hombre y la raíz de todos los demás" (VI 303) porque es la técnica primigenia que permite una resistencia e independencia respecto al medio. Pero en un sentido más metafísico, el fuego ejemplifica la capacidad destructiva del hombre, una de sus más íntimas y particulares cualidades.
} 
el caparazón pertenece al cuerpo de la tortuga" (Arendt, 2005, p. 177). Como el propio Heisenberg comenta, "Acaso un día los más diversos artefactos técnicos formarán parte integrante del hombre, como su concha lo es del caracol o su tela lo es de la araña" (Heisenberg, 1969, p. 18). La técnica extrasomática del ser humano podría ser entendida como el exoesqueleto de los crustáceos y otros animales, el cual, pese a ser en cierto modo externo, es constitutivo de su vida. Un cangrejo sin su exoesqueleto sería una masa informe incapaz de vivir, lo mismo que sucedería con un ser humano que careciera de su técnica extrasomática.

Esta tesis, muy afín a la orteguiana idea de sobrenaturaleza, queda reafirmada en su carácter eminentemente biológico con la siguiente afirmación de Heisenberg: "Cuando dirigimos la atención a casos semejantes, la técnica, más bien que fruto del consciente humano esfuerzo por ampliar el poderío material del hombre, casi parece constituir un vasto proceso biológico, gracias al cual las estructuras inherentes al organismo humano van siendo paulatinamente transportadas al medio ambiente en que vive el hombre" (Heisenberg, 1969, p. 19). Una idea que Arendt comentará señalando que si nos fijamos en el hombre y su actuación sobre la tierra:

... se hace manifiesto que todas sus actividades, observadas desde un punto de vista del universo suficientemente alejado y ventajoso, no parecerían actividades sino procesos, de manera que, como ha señalado recientemente un científico, la motorización moderna parecería un proceso de mutación biológica en el que los cuerpos humanos comienzan gradualmente a cubrirse de caparazones de acero. Para el observador situado en el universo, esta mutación no sería ni más ni menos misteriosa que la que surge ante nuestros ojos en esos pequeños organismos vivos que combatimos con antibióticos y que misteriosamente han desarrollado nuevas fuerzas que nos hacen frente (Arendt, 2005, pp. 339-340)

Esta idea, que Arendt critica duramente, encaja muy bien con nuestro planteamiento. Desde esta perspectiva, y en contra de lo que pudiera parecer, se desecha por principio la comprensión de la herramienta como prolongación del cuerpo humano. Como acertadamente explica Stiegler, "La pró-tesis no es una simple prolongación del cuerpo humano, es la constitución de ese cuerpo en tanto que "humano"” (2002, p. 229) ${ }^{13}$. Decir que el hacha es la prolongación de

\footnotetext{
${ }^{13}$ En este sentido, las ideas de Stiegler no tienen desperdicio, y en La técnica y el tiempo podemos por ejemplo leer que "El problema que se plantea aquí es el de la evolución no sólo biológica de ese ser esencialmente técnico que es el hombre" (Stiegler, 2002, p. 80). "La evolución de la "prótesis", continuará el filósofo francés- que no es ella misma viva, y por la que el hombre sin embargo se define en tanto que ser vivo, es lo que constituye la realidad de la evolución del hombre tal y como si, con él, la historia de la vida tuviera que continuar por otros medios diferentes de la vida: es la paradoja de un ser vivo caracterizado en sus formas de vida por un ser no-vivo -o por las trazas que
} 
la mano sería igual de gratuito que decir que la mano es prolongación del brazo. La cuestión no sólo está en que el hacha no sea una prolongación de la mano, y que sea una parte del cuerpo (un órgano) de pleno derecho igual que la mano; sino que, si habláramos en estos términos del hacha de sílex como "una prolongación de la mano", por lo mismo habría que decir que la mano es una "prolongación del hacha". La clave está en que si bien no puede haber hacha sin mano, tampoco puede haber mano sin hacha. Entre ambas hay una coevolución y cooriginamiento, y no puede entenderse una como una consecuencia unidireccional de la otra, la dependencia es mutua y bidireccional.

\section{La sobrenaturaleza como esfera inmunológica: Sloterdijk}

En todo caso, si hay un autor reciente que ha recogido de diversas maneras esta idea orteguiana de la sobrenaturaleza, es P. Sloterdijk. Ya en su breve ensayo Normas para el parque humano el filósofo alemán definía al ser humano del siguiente modo: "Los hombres son seres que se cuidan y se protegen por sí mismos y, vivan donde vivan, generan alrededor suyo el entorno de un parque" (2006b, p. 75). Este entorno de parque podría traducirse sin mucho problema por la sobrenaturaleza orteguiana, pues su significado es prácticamente el mismo. Lo cual no es extraño cuando vemos que algunas de las bases antropológicas desde las que parte el planteamiento sloterdijkiano coinciden casi por completo con las bases antropológicas orteguianas. El ejemplo más claro lo podemos ver en Esferas I cuando Sloterdijk afirma que "Nunca han vivido los seres humanos en inmediatez a la llamada naturaleza" (2014a, p. 52), y que los seres humanos "Son seres vivos que se esfuerzan por ser seres en suspenso" (2014a, p. 52). Esta necesidad que Sloterdijk ve en el hombre de sostenerse artificialmente en un medio hostil es, como ya expusimos, una de las claves del planteamiento orteguiano.

En Normas para el parque humano Sloterdijk también apuntará claramente a la cuestión de la sobrenaturaleza humana al entender al ser humano como animal doméstico. Como venimos explicando, la sobrenaturaleza es el auténtico lugar del hombre, allí donde se siente, valga la expresión, "en casa"14. Por ello no puede subestimarse el significado filosófico de la casa, hasta el punto de que el hombre podría definirse precisamente por ser un "animal que vive en casas". Que el hombre tenga intimidad, está también en directa relación con su necesario

su vida deja en el no-vivo" (2002, p. 80).

14 J. Diamond pone de relieve el "sedentarismo que ha caracterizado a las poblaciones humanas" (2016, p. 308). 
vivir en casas, en habitáculos donde se resguarda del exterior creando un interior. Siguiendo algunas intuiciones nietzscheanas, Sloterdijk, entiende que el surgimiento del hombre como animal doméstico está inseparablemente unido, como la etimología de domus ya nos indica, a la costumbre de vivir en casas (Cf. Sloterdijk, 2006, p. 60). La creación de casas es uno de los ejemplos más visibles de la sobrenaturaleza humana, y probablemente uno de los más fundamentales.

En Esferas puede verse, de manera más clara todavía, cómo Sloterdijk relaciona esta cuestión de la vivienda con el que a partir de este y otros textos pasará a ser uno de sus temas preferidos: la inmunología. Así pues, en Esferas III podemos ver cómo Sloterdijk propone "una definición dinámica de la vivienda como un sistema espacial de inmunidad" (2014b, p. 408), especificando, en términos de resonancia muy orteguiana, que "Desde el punto de vista inmunológico, habitar es una medida de defensa por la que se delimita un ámbito de bienestar frente a invasores y otros portadores de malestar" (2014b, p. 408) Ya en Esferas I este autor había definido su concepto fundamental de esfera en torno a este problema de la inmunología, como puede verse la siguiente explicación, bajo la que la sobrenaturaleza orteguiana parece estar continuamente palpitando: "Vivir en esferas significa generar la dimensión que pueda contener seres humanos. Esferas son creaciones espaciales, sistémico-inmunológicamente efectivas, para seres estáticos en los que opera el exterior" (2014a, p. 37)

No obstante, si hay una obra donde las reflexiones sobre la inmunología alcanzan un desarrollo más específico y acabado es en el reciente Has de cambiar tu vida, donde Sloterdijk desarrollará su concepción del ser humano como ser ejercitante. Estos ejercicios desplegados por los seres humanos crean sistemas inmunitarios -caparazones, sistemas de protección, al fin y al cabodesde los cuales el hombre puede hacer frente a su entorno. De este modo, hasta cierto punto podría decirse que Sloterdijk va más lejos que el propio Ortega en su caracterización de la relación entre organismo y circunstancia como antagónica y hostil, entendiendo que los organismos vivos son principalmente y antes que nada sistemas inmunitarios que anticipan y se protegen continuamente de las agresiones provenientes del entorno. Esta idea, que Sloterdijk sólo ve parcialmente anticipada en Luhmann y su planteamiento metabiológico

\footnotetext{
${ }^{15}$ A este respecto cabría señalar la común oposición de Ortega y Sloterdijk a un planteamiento como el Heideggeriano, que en su conferencia de Darmstad Construir, habitar, pensar defenderá que el construir no surge como medio para el habitar, para hacer habitable lo previamente inhóspito, sino que "Habitamos no porque hayamos construido, sino que construimos y hemos construido, en cuanto habitamos" (Heidegger, 1997, p. 203), y esto porque "Ser hombre quiere decir: ser como mortal sobre la Tierra, quiere decir: habitar" (Heidegger, 1997, p. 202).
} 
(Sloterdijk, 2013, p. 423), tiene una gran relación con el planteamiento orteguiano, como muestra el siguiente texto del filósofo alemán:

En la plétora de novedades cognitivas que han visto la luz del sol de la modernidad no hay ninguna que sea comparable, ni de lejos, con la aparición y el conocimiento de los sistemas inmunológicos en la biología de finales del siglo XIX. Desde entonces nada puede seguir siendo como era en las ciencias que versan sobre las entidades integrales -los organismos animales, las especies, las «sociedades», las culturas-. Sólo con titubeos se ha empezado a entender que los llamados sistemas se convierten propiamente en sistemas, los seres vivos en seres vivos o las culturas en culturas gracias precisamente a dispositivos de carácter inmunológico. Sólo en virtud de sus cualidades inmunitarias aquéllos ascienden al rango de unidades autoorganizadas que se conservan y reproducen en una relación constante con un mundo circundante invasivo e irritante tanto en potencia como en acto. Tales prestaciones se desarrollan de un modo especialmente impresionante en los sistemas biológicos inmunitarios -cuyo descubrimiento se remonta a las investigaciones hechas por Ilya Mechnikov y los discípulos de Robert Koch, sobre todo Paul Ehrlich, a finales del siglo XIX (Sloterdijk, 2013, pp. 21-22)

No es difícil ver en este y otros textos ecos orteguianos, sobre todo su idea decisiva de que el organismo siempre está en una circunstancia hostil, que le ataca y amenaza, y frente a la cual tiene que imponerse creando una sobrenaturaleza protectora o, podríamos decir con Sloterdijk, inmunitaria. Esta inmunización que en Ortega se lograría mediante la creación de una sobrenaturaleza en Sloterdijk se tematiza bajo el término de "ejercicio": "Defino como ejercicio cualquier operación mediante la cual se obtiene o se mejora la cualificación del que actúa para la siguiente ejecución de la misma operación" (2013, p. 17), aludiendo precisamente a "la ley fundamental de la antropotécnica: el efecto retroactivo de todas las acciones y de todos los movimientos sobre su propio autor" (2013, p. 407). Las antropotécnicas no serían otra cosa que "los procedimientos de ejercitación, físicos y mentales, con los que los hombres de las culturas más dispares han intentado optimizar su estado inmunológico frente a los vagos riesgos de la vida y las agudas certezas de la muerte" (Sloterdijk, 2013, p. 24).

Esta optimización del estado inmunológico frente a los riesgos de la vida sería, traducido al vocabulario orteguiano, la creación de una sobrenaturaleza (material y espiritual) en la que el hombre esté protegido de su circunstancia y pueda llevar a cabo su vida humana. En un sentido aún más radical, Sloterdijk dirá que "ya la simple conservación de la forma corporal -o mejor, la forma neurofísica- no ha de ser entendida sino como el efecto de un entrenamiento no declarado como tal" (2013, p. 519), aludiendo así a una "sorda autopoíesis" (2013, p. 519) que constituiría de principio a fin al ser humano. Por ello, puntualizará el filósofo alemán, "Quien permanezca idéntico consigo mismo se 
confirma con ello como un sistema experto en funcionamiento, que se ha expecializado en el continuo autorrestablecimiento de sí mismo" (Sloterdijk, 2013, p. 519).

Como último apunte de la propuesta sloterdijkiana podríamos aludir a su comprensión de las religiones, y especialmente de la religión cristiana, como complejos sistemas de ejercicios que, en último término, consisten en un una inmunización y potenciamiento de la vida humana. La especificidad cristiana radicaría en que es la religión donde se alcanza una mayor claridad y consciencia respecto de sí misma, cargándose así de responsabilidad. En este sentido, explica Sloterdijk que "Ya los primeros cristianos empezaron a transformar toda su vida en un experimento, para asemejarse al Hombre-Dios: «Nos autem im experimentis volvimur», escribió Agustín en sus Confesiones" (2013, p. 405). A este respecto, es muy significativo que la base para el auge y primado de la creación en la Modernidad y antes en el Renacimiento estuviera ya prefijado y totalmente marcado por el cristianismo. Pues, como señala Sloterdijk, "Los hombres de la Edad Moderna añadieron al experimentalismo ascético de los antiguos el técnico y el artístico y, finalmente, el político" (2013, p. 405); y no lo idearon en contra del cristianismo, recuperando una Grecia mítica como cierta historiografía imperante nos ha llevado a creer. En este sentido, el testimonio de un autor cristiano como Rahner es muy revelador: "De acuerdo con la declaración del jesuita Rahner, la obligación y el deseo de manipularse a sí mismo formarían parte del ethos del hombre responsable" (Sloterdijk, 2000, p. $17)^{16}$. Aunque no podemos aquí ahondar mucho en esta cuestión, es claro que esta visión del cristianismo nos pone sobre la pista de por qué la cristiana no sólo es la religión más extendida en el mundo, sino por qué las categorías que ha legado a Occidente, las categorías que -podríamos decir- constituyen a Occidente, son las que ha permitido al mundo occidental imponerse a todas las otras formas de vida y sus sistemas de ejercicios, como diría Sloterdijk, de técnicas y creencias, como diría Ortega. Las intuiciones antropológicas del cristianismo, su énfasis en la necesidad que tiene el menesteroso ser humano de una sobrenaturaleza protectora de la que, sin embargo, debemos responsabilizarnos nosotros mismos, la ha convertido en una de las creaciones más exitosas de la historia.

\footnotetext{
16 "Debe querer ser el hombre operable, incluso si la dimensión y justo modo de tal automanipulación resultan todavía oscuros... Pero es cierto: el futuro de la automanipulación del hombre ya ha comenzado" (Rahner (1966), citado por Sloterdijk, 2000, p. 17).
} 


\section{Conclusiones}

El recorrido a algunas sugerentes ideas de autores tan heterogéneos como Ortega, Stiegler y Sloterdijk nos ha proporcionado una interesante perspectiva sobre la capacidad técnica, o en un sentido más general, sobre la capacidad creativa, del ser humano. Las distintas tematizaciones que llevaron a cabo estos autores, como sobrenaturaleza, exteriorización o esfera inmunológica, suponen concreciones al fenómeno genérico de la creatividad, de la capacidad poiética, que aquí hemos relacionado principalmente con la técnica, pero que durante mucho tiempo se englobaba bajo el nombre más genérico aún de cultura. En cualquier caso, el hilo rojo que recorre estas distintas aproximaciones y que acerca, pese a sus diferencias, los planteamientos de estos autores, es la importancia que este rasgo específico tiene para el ser humano y su vida. Es precisamente esta capacidad creadora la que define al ser humano, una creación que, en los tres casos -en Ortega, en Stiegler y en Sloterdijk- tiene que ver con una forma peculiar de organizarse la vida en la que ésta se protege por anticipado y produce, de este modo, una capa protectora que a la postre es el humus de donde surge ese extraño ser que es el ser humano. Creemos, además, que estas reflexiones resultan muy útiles como paradigma desde el que comprender nuestro tecnificado mundo de hoy, un mundo en el que la sobrenaturaleza de la que hablaba Ortega ha alcanzado una extensión incomparable, y que, por tanto, no podemos permitirnos dejar de analizar y de intentar comprender.

\section{Bibliografía}

ARENDT, H. (2005). La condición humana. Barcelona: Paidós Surcos.

Atencia PÁEZ, J. M. (2003). "Ortega y Gasset meditador de la técnica". Argumentos de Razón Técnica, $\mathrm{n}^{\circ}$ 6, pp. 61-95.

Blumenberg, H. (2011). Descripción del ser humano. Trad. Griselda Mársico. Buenos Aires: Fondo de cultura económica.

Cerezo Galán, P. (1984). La voluntad de aventura. Aproximamiento crítico al pensamiento de Ortega y Gasset. Barcelona: Ariel.

DiÉGueZ LuCENA, A. (2013). "La filosofía de la técnica de Ortega como guía para la acción. Una comparación con Heidegger”. Revista Internacional de Tecnología, Conocimiento y Sociedad, Vol. 2, nº 1, pp. 73-97.

ECHEVERRÍA EZPONDA, J. (2000). "Sobrenaturaleza y sociedad de la información: La Meditación de la técnica a finales del siglo XX". 
Revista de Occidente, $\mathrm{n}^{\mathrm{o}} 228$ (Ortega y la sociedad tecnológica), pp. 1932

Ellacuría BeAscoecheA, I. (1996). Técnica y vida humana en Ortega y Gasset: Estudio de «Meditación de la técnica». Escritos filosóficos, vol. I, San Salvador: UCA, 1996, pp. 415-518.

GeHLEN, A. (1980). El hombre: su naturaleza y su lugar en el mundo. Salamanca: Sígueme.

HeIDEgGer, M. (1997). Filosofía, ciencia y técnica. Prólogos de Francisco Soler y Jorge Acevedo. Santiago de Chile: Editorial Universitaria.

HEISENBERG, W. (1969). La imagen de la naturaleza en la física actual. Barcelona: Seix Barral. Trad. Gabriel Ferraté.

MARTín CABRero, F. J. (1999). La tradición velada. Ortega y el pensamiento humanista. Madrid: Biblioteca Nueva.

ORTEGA Y GASSET, J. (2004-2010). Obras completas. Tomos I-X. Madrid: Taurus.

SLOTERDiJK, P. (2006). Normas para el parque humano: una respuesta a la carta sobre el humanismo de Heidegger. Trad. Teresa Rocha Barco. Madrid: Siruela.

- (2013). Has de cambiar tu vida. Sobre antropotécnica. Traducción de Pedro Madrigal. Valencia: Pre-textos.

- (2014a). Esferas I. Madrid: Siruela. Trad. Isidoro Reguera.

- (2014b). Esferas III. Madrid: Siruela. Trad. Isidoro Reguera.

STIEGLER, B. (2002). La técnica y el tiempo 1. El pecado de Epimeteo. Trad. Beatriz Morales Bastos. Guipuzkoa: Hiru. 
